\title{
A INSUFICIÊNCIA DO POSITIVISMO DE FERRAJOLI PARA EFETIVAR OS DIREITOS FUNDAMENTAIS QUE DEFENDE
}

THE FAILURE OF FERRAJOLI'S POSITIVISM FOR EFFECT FUNDAMENTAL RIGHTS DEFENDING

Núbio Pinhon Mendes Parreiras ${ }^{1}$

PUC Minas

\begin{abstract}
Resumo
O conceito de Direito de Ferrajoli, por ser positivista, acaba por negar validade aos direitos fundamentais que não atendem às suas exigências de positivação, o que evidencia sua ineficácia em casos de desatenção do legislador, a exemplo do brasileiro em relação à necessidade de lesividade para as proibições penais.Já o conceito de Alexy, por ser nãopositivista, reconhece alguns princípios fundamentais, independente de previsão legal, especialmente quando a aplicação da norma provocar uma situação de extrema injustiça, tal qual a punição de ação sem lesão significante. Este artigo contrasta as duas concepções de Direito e demonstra a ineficácia do positivismo de Ferrajoli em garantir direitos fundamentais.
\end{abstract}

Palavras-chave

Conceitos de Direito. Direitos fundamentais. Direito Penal.

\begin{abstract}
Ferrajoli's concept of Law, being a positivist, ends up negating the validity of fundamental rights that do not meet your requirements of positivation, which shows its ineffectiveness in cases of the inattention of legislator, in example, Brazilians with relation to the need of harmfulness in criminal probibitions. But the concept of Alexy, to be non-positivistic, recognizes some fundamental principles, regardless of legal provisions, especially when the application of the rule trigger a situation of extreme injustice, like the punishment of action without significant injury. This article contrasts the two conceptions of Law and demonstrates the ineffectiveness of Ferrajoli's positivism to guarantee fundamental rights.
\end{abstract}

${ }^{1}$ Mestrando em Direito pela PUC Minas. 


\section{Keywords}

Law concepts. Fundamental rights. Criminal law.

\section{INTRODUÇÃO}

A teoria do garantismo penal de Luigi Ferrajoli é, antes de tudo, uma obra sobre teoria do Direito, visando uma configuração teórica alicerçada em axiomas, penais e processuais penais, historicamente elaborados para a garantia de direitos fundamentais.

E esta concepção de Direito de Ferrajoli, por ter uma filiação positivista, possui sérias dificuldades em reconhecer validade a direitos fundamentais não positivados dentro de suas exigências, o que pode influenciar a prática penal a não reconhecer princípios não suficientemente positivados, como o princípio da insignificância.

Daí que tal concepção legitima a expansão do Direito Penal, quando delimitado por direitos fundamentais positivados, razão pela qual será objeto de questionamento neste estudo.

O conceito de Direito de Robert Alexy, por outro lado, sendo pautado na conexão com a Moral (conceito não-positivista), admite a validade de princípios não positivados, especialmente quando a aplicação da norma resultar em extrema injustiça.

Assim, este estudo se propõe a questionar o garantismo de Ferrajoli, identificando como falha principal a não guarida a direitos fundamentais não previstos, dentro de suas exigências, em lei, o que ficará evidenciado com um contraste com a concepção de Alexy.

\section{O CONCEITO E A VALIDADE DO DIREITO}

A filosofia do Direito compreende duas dimensões fundamentais, a da concepção/conceito e a da aplicação do Direito, conforme Trivisonno (2015). Este trabalho se limitará à discussão acerca do conceito de Direito, em especial no que se refere ao Direito Penal. 
A questão dos conceitos de Direito, remonta há pelo menos dois mil anos, desde Xenofonte, conforme lembra Alexy (2010, p. 03 e 2015, p. 272), possuindo como tema básico a relação do Direito com a Moral, de modo que os adeptos do positivismo defendem a separação, como Kelsen (1994) e Ferrajoli (2010, 2012 e 2012a). Já os não-positivistas, propõem a conexão entre o Direito e a Moral, como Streck ${ }^{2}$ (2014a) e Alexy (2010, 2011 e 2015).

Portanto, este estudo destacará dois conceitos de Direito, para a análise da capacidade deles resguardarem os direitos fundamentais, a começar pelo garantismo penal de Ferrajoli, ou o "constitucionalismo garantista como jus-positivismo reforçado" (FERRAJOLI, 2012, p. 22). Após, será analisado o conceito de Direito de Alexy, ou o "não-positivismo inclusivo" (ALEXY, 2015, p. 316).

\subsection{O garantismo/positivismo de Luigi Ferrajoli}

Como já mencionado, o próprio Ferrajoli imputa ao seu conceito de Direito uma filiação positivista - muito embora aprimorada uma vez que conserva a separação do Direito e da Moral.

O reforço do garantismo ao juspositivismo, conforme explica Ferrajoli (2012 e 2012a), se dá tanto por uma adição ao positivismo jurídico do "dever-ser" (substancial), positivado ao lado do "ser" (formal) - este exclusivo no positivismo normativista de Kelsen, por exemplo -, quanto por um acréscimo ao Estado de Direito da possibilidade de controle de constitucionalidade ou autorreforma, inclusive da atividade legislativa.

Diante disto, o garantismo, ou juspositivismo crítico (FERRAJOLI, 2010, p. 805) traz uma nova concepção de validade e de

${ }^{2}$ Importante ressaltar que Lenio Streck, apesar de ser um franco crítico ao modelo de aplicação de Robert Alexy, especialmente à ponderação, também rejeita a separação entre o Direito e a Moral, no entanto, com argumentos distintos aos de Alexy, falando em cooriginariedade entre ambos. 
vigência da norma, aperfeiçoando aquela de Kelsen (1994), que se limitava à regulação das formas, justamente por abarcar os conteúdos das normas.

Assim, com o princípio da legalidade, que compreende o princípio da mera legalidade (nullum crimen sine lege), o juiz fica sujeito apenas às leis vigentes (existentes) e válidas (legitimação interna, conforme as normas superiores, formal e substancialmente), possibilitando o garantismo de Ferrajoli uma autocorreção/autorreforma do sistema, embora limitada às antinomias normativas.

Com isto, dois dogmas juspositivistas (sobretudo o de Kelsen) são derrubados pelo garantismo (juspositivismo crítico): a obrigação de o juiz aplicar qualquer lei, uma vez que ele deve declarar inválidas as que são; e a impossibilidade do juiz valorar a lei, como na teoria pura do Direito de Kelsen (1994), já que ele deve valorar a validade.

Por fim, no que toca à dimensão penal material ${ }^{3}$, como explica Ferrajoli (2010, p. 38/39), o garantismo possui como elemento epistemológico o convencionalismo penal, que resulta da legalidade estrita, que, por sua vez, possui duas faces: a primeira é a do princípio da reserva legal, mera legalidade - já mencionado acima -, que submete o juiz a punir na forma e no que prevê a lei; já o segundo é o princípio da estrita legalidade, que, direcionado ao legislador, exige do mesmo a taxatividade e precisão empíricas para criminalizar, vedando, ainda, a criminalização de pessoas (e não fatos), com caráter constitutivo (e não regulamentar), tal qual tipos penais que não descrevem fatos/ações.

Desse modo, Ferrajoli afirma que a reserva legal produz dois efeitos básicos:

(...) O primeiro é a garantia para os cidadãos de uma esfera intangível de liberdade, assegurada pelo fato de que, ao ser

${ }^{3}$ Isto porque o garantismo abrange duas dimensões: o convencionalismo, de Direito Penal material; e o cognitivismo, de âmbito processual, conforme Ferrajoli (2010, p. 39/40). Os estritos limites deste trabalho não permitem o estudo desta segunda, processual. 
punível somente o que está proibido na lei, nada do que a lei não proíba é punível, senão que é livre ou está permitido: por jus entende Hobbes a 'liberdade que a lei me confere para fazer qualquer coisa que a lei não me proíba, e de deixar de fazer qualquer coisa que a lei não me ordene.' O segundo é a igualdade jurídica dos cidadãos perante a lei: as ações ou os fatos, por quem quer que os tenha cometido, podem ser realmente descritos pelas normas como 'tipos objetivos' de desvio e, enquanto tais, ser previstos e provados como pressupostos de igual tratamento penal; enquanto toda préconfiguração normativa de 'tipos subjetivos' de desvio não pode deixar de referir-se a diferenças pessoais, antropológicas, políticas ou sociais e, portanto, de exaurir-se em discriminações apriorísticas. (2010, p. 40)

Desse modo, como se observa, o garantismo de Ferrajoli é compreendido basicamente nessa nova noção positivista, destacando como suas peculiaridades a positivação do dever-ser e a possibilidade de autocorreção do sistema com o controle de constitucionalidade de suas normas, dentro dos limites de sua nova concepção de validade normativa.

Mas, como é realizada essa positivação do dever-ser, que possui estreita relação com a noção de princípios de Luigi Ferrajoli, será analisado no tópico a seguir.

\subsubsection{Sua noção geral dos princípios}

O garantismo penal de Ferrajoli estabelece parâmetros para a análise de graus de satisfação do sistema garantista (SG), na medida em que, quanto mais axiomas/princípios do SG são incorporados ao sistema, mais garantista este se torna (FERRAJOLI, 2010). 
Este sistema garantista é composto por dez axiomas ${ }^{4}$ (FERRAJOLI, 2010, p. 91), sendo os sete primeiros de ordem do Direito Penal material, e os três demais de matéria processual penal.

Assim, para o autor, é com a positivação, dentro de suas exigências, destes princípios/axiomas fundamentais (incorporação limitativa) às normas superiores, especialmente à Constituição, que se assegura a proteção do dever-ser, sendo, o contrário, limitador do cumprimento dos direitos fundamentais (FERRAJOLI, 2010, p. 333/336).

Aí é que se encontra o aspecto substancial do Direito positivado, donde se possibilita a autocorreção do sistema diante de eventual antinomia entre as normas hierarquizadas, com a avaliação da (in)validade da norma, não se limitando, como dito acima, ao aspecto formal (violação de procedimento, incompetência do órgão etc.), senão considerando igualmente os aspectos de justiça material, ou seja, o conteúdo (ou substância) da norma em relação à superior.

Diante disto, a legalidade, neste modelo, não apenas condiciona a validade das normas, mas também é condicionada às normas constitucionais (FERRAJOLI, 2012, p. 22/23).

Assim, os princípios, em Ferrajoli, são estes valores positivados, dentro de exigências, nas normas superiores na escala hierárquica das normas, de modo que o desrespeito destes, por norma inferior, exige o controle de constitucionalidade pelos juízes, para posterior reconhecimento da invalidade.

\subsection{O não-positivismo inclusivo de Robert Alexy}

\footnotetext{
${ }^{4}$ A1 Nulla poena sine crimine; A2 Nullum crimen sine lege; A3 Nulla lex (poenallis) sine necessitate; A4 Nulla necessitas sine injuria; A5 Nulla injuria sine actione; A6 Nulla actio sine culpa; A7 Nulla culpa sine judicio; A8 Nullum judicium sine accusatione; A9 Nulla accusation sine probatione; A10 Nulla probatio sine defensione.
} 
Diferente de Ferrajoli e os demais positivistas, Alexy postula por uma conexão entre o Direito e a Moral, apesar de fraca (ALEXY, 2011, p. 58), já que apenas diante de extrema injustiça, como se verá neste trabalho.

O conceito de Direito de Alexy ${ }^{5}$ possui três formulações que se complementam: o argumento da correção; o argumento da injustiça; e o dos princípios (ALEXY, 2010, p. 35; ALEXY, 2011, p. 151/152).

Em relação ao argumento da correção, a base dos demais, ensina que o sistema jurídico sempre deve formular uma pretensão à correção, sob pena de lhe faltar a classificação de jurídico. Agora, caso respeite esta pretensão, mas de forma insatisfatória, é qualificado como defeituoso (ALEXY, 2010, p. 35; ALEXY, 2011, p. 43 e 152).

Já o argumento da injustiça ${ }^{6}$, define a relação entre os três elementos clássicos do Direito, conservando dois positivistas e acrescentando um não positivista, sendo, respectivamente: a legalidade conforme o ordenamento e a eficácia social; e a correção material.

Assim, a validade da totalidade das normas constitucionais e infraconstitucionais (legalidade conforme o ordenamento), socialmente eficazes (eficácia social), depende que estas não sejam extremamente

5 O conceito de Direito de Alexy é analisado sobre duas perspectivas relacionadas à argumentação: a do participante (advogados, juízes, cientistas jurídicos etc.); e a do observador. Interessa a este estudo tão somente a perspectiva de argumentação do participante. Esta distinção é melhor retratada em Alexy (2011, p. 30/31).

${ }^{6}$ Robert Alexy menciona, para a análise do argumento da injustiça, oito argumentos, em relação às normas individuais, e duas teses, referentes aos sistemas jurídicos. Os argumentos são: o linguístico; o da clareza; o da efetividade; o da segurança jurídica; o do relativismo; o da democracia; o da inutilidade; e o da honestidade. Já as teses: a da irradiação; e a do colapso. Os limites deste trabalho não comportam uma análise pormenorizada de tais questões. Mas, para aprofundar no tema, ver Alexy (2011, p. 49/83). 
injustas ${ }^{7}$ (conexão fraca). Ou seja, à validade da norma não basta a dimensão real/factual do Direito (dos dois elementos positivistas), necessitando de uma ideal/crítica, da correção material (ALEXY, 2010, p. 40; ALEXY, 2011, p. 48 e 152).

Por fim, no que toca ao argumento dos princípios, afirma que há, no Direito, princípios e outros argumentos para satisfazer a pretensão à correção. Com isso, apesar de o direito positivo ser aberto - passível de lacunas, contradições etc. -, para os não positivistas, os princípios possuem o mesmo caráter jurídico que as regras, não estando fora do sistema, o que os torna aptos a solucionar os casos difíceis. Já os positivistas, como Kelsen (1994), atribuem ao juiz, nestas situações, a tarefa de criar outro direito, decidindo com critérios não jurídicos.

Para o argumento dos princípios, três teses são formuladas: a da incorporação; a da moral; e a da correção. Por comporem a ideia de princípio do autor, serão discutidas a seguir.

\subsubsection{Sua noção geral dos princípios}

Enquanto Ferrajoli (2010) apresenta uma visão positivista sobre os princípios, conforme já visto, as três teses apresentadas por Alexy (2010, p. 68; 2011, p. 83 e 154) conduzem a uma conexão entre o direito e a moral, sendo: a tese da incorporação; a da moral; e a tese da correção.

Antes de avançar nas referidas teses, é a partir da distinção entre regras e princípios que é estruturado o argumento dos princípios. É proposto por Alexy (2011, p. 85) uma reformulação da teoria dos princípios de Dworkin, distinguindo as regras dos princípios, vendo estes como "razões prima facie" (mandamentos de otimização, aplicados através da ponderação), e elas como "razões definitivas" (aplicados com a subsunção),

7 Importante destacar que, conforme lembra Alexy (2010, p. 40, 2011, p. 48/49, ou 2015, p. 250/251 e 276), esta questão da extrema injustiça fora formulada por Gustav Radbruch, após abandonar a filiação positivista. 
caso não haja estabelecimento de exceção. Algumas considerações sobre esta formulação de Alexy podem ser encontradas, também, em Neves (2014, p. 63/69).

Desse modo, a começar pela tese da incorporação, Alexy (2010, p. 71/74; 2011, p. 86/90; 2015, p. 261/264) afirma que todo sistema jurídico minimamente desenvolvido, é incorporado por princípios, além das regras. $\mathrm{E}$ os positivistas, inclusive Luigi Ferrajoli, concordam com isto, defendendo, contudo, que se trata de uma questão de direito positivo, mas não de conexão com a moral.

Ocorre que, com a pretensão de correção, todo caso difícil deve ser decidido com a ponderação de princípios, como parte integrante das sentenças, o que indica, à primeira vista, uma relação do Direito com a Moral.

Porém, a tese da incorporação, por si só, não demonstra claramente uma vinculação do Direito com a Moral. A tese da moral de Alexy (2010, p. 74/76; 2011, p. 90/92; 2015, p. 264/265) tenta evidenciar esta relação, advogando que, além dos sistemas jurídicos serem incorporados por princípios, dentre estes há os que integram uma moral qualquer (correta ou errada, conexão fraca). Ocorre que, para alguns positivistas, nos casos duvidosos, os princípios morais também fundamentam a decisão, sendo, no entanto, por critérios extrajurídicos. A diferença é que a tese da moral incorpora ao sistema jurídico estes princípios morais, donde se extrai a conexão.

Mas a conexão com uma moral qualquer não é suficiente, já que são incluídas as morais erradas/injustas. Assim, Alexy (2010, p. 76/81;2011, p. 92/97) acrescenta uma terceira tese, a da correção, que impõe ao conteúdo dos princípios uma origem proveniente de uma moral correta. E o critério para definir não é subjetivo, como questionaria Ferrajoli (2010), mas objetivo, não abarcando qualquer ordem jurídica totalitária, como o nacional-socialismo, mas dentro de uma fundamentabilidade minimamente racional. Contudo, esta conexão deve ser fraca, já que a forte retira o caráter jurídico da norma independente se a injustiça é extrema ou não. 
Destaca-se, neste primeiro momento, algumas diferenças cruciais entre a noção de princípios de Ferrajoli e Alexy, se sobressaindo, mais claramente, pelo menos dois pontos.

Enquanto Ferrajoli acredita que os princípios morais estão fora do Direito, Alexy defende que são integrados pelo ordenamento e são utilizados com critérios jurídicos.

Num segundo momento, extrai-se do positivismo de Ferrajoli que a noção de validade da norma, no aspecto material, é atrelada à escala hierárquica normativa, se limitando o controle ao respeito às normas superiores, independente se respeitam ou não os direitos fundamentais, sendo estes apenas critérios para averiguar o grau de garantismo. Já Robert Alexy incorpora ao seu conceito de validade a vedação das normas extremamente injustas, o que retiraria a sua qualidade jurídica.

Com estas considerações, passemos a discutir os direitos fundamentais no âmbito penal.

\section{OS DIREITOS FUNDAMENTAIS NO ÂMBITO PENAL}

A importância dos direitos fundamentais é por demais extensa para as pretensões deste estudo, porém, no que toca ao conceito de Direito Penal, aqui estudado, algumas questões devem ser observadas.

Como se sabe, a concepção de um Direito democrático contemporâneo - seja para os positivistas ou para os não positivistas pressupõe a segurança dos direitos fundamentais dos membros da sociedade, sendo tal atribuição destinada a todos os ramos jurídicos.

Daí que, como lembra Roxin (2013, p. 29/30), o tratamento dos direitos fundamentais no Direito Penal é realizado de forma subsidiária, devendo incidir apenas nas matérias em que os demais ramos (civil, comercial, administrativo etc.) se demonstraram insuficientes na proteção dos bens jurídicos.

Assim, ao Direito Penal são destinados os bens jurídicos em que os instrumentos das demais áreas do Direito não se mostraram 
suficientes para coibir de lesões (ou perigo de lesão), justamente por ser a esfera penal a ultima ratio jurídica (TAVARES, 2002, p. 202).

Para tanto, mostra-se necessário analisar alguns aspectos da necessidade de lesão (ou perigo de lesão) a bem-jurídico penal, o que se fará no tópico a seguir.

\subsection{A lesividade e os bens jurídicos}

Das variadas abordagens que se pode referir a bem-jurídico penal e a questão da lesividade, três nos interessam aqui: a alteridade; a pessoalidade; e a proporcionalidade.

No que diz respeito à alteridade, conforme Zaffaroni et al (2013, p. 225), com a liberdade de expressão intelectual, crença, artística, científica, dentre outras asseguradas na Constituição da República (artigo 5º), o Estado não pode impor uma moral, e sim garantir a liberdade moral, não podendo punir este exercício. Daí emerge a necessária alteridade da conduta para eventual reprovação penal.

E é desta alteridade que se define o bem jurídico, em modelos republicanos, como direito do cidadão, de carne e osso, e não como a vontade do Estado (FERRAJOLI, 2010; ZAFFARONI et al, 2013).

Para tanto, deve-se destacar que, como já afirmado acima, com o princípio da lesividade, as proibições penais se justificam somente quando há afetação ou perigo de lesão do bem jurídico.

Daí que, como demonstrado por Zaffaroni et al (2013, p. 226/227), se deve tomar cuidado na conceituação, não equiparando o bem jurídico lesionado ou exposto a perigo com o bem jurídico tutelado. Isto porque nada prova que há proteção de bens jurídicos, senão o confisco dos conflitos que atingem ou expõem a perigo bem jurídico, para possível solução. Afinal, como mencionado pelo autor, no homicídio não há tutela da vida.

Já a pessoalidade, para além da formulação criticada por Roxin (2013, p. 19) que se limitava a bens jurídicos individuais, admite-se uma 
dimensão coletiva. Contudo, como explicado por Tavares (2002, p. 202/203), ainda que "classificado" como coletivo, como o "fisco", deve ser fundamentado com o fim de proteção da pessoa humana. Referida compreensão é também encontrada em Roxin (2013, p. 18/19).

Ainda, no que se refere à pessoalidade, muito bem lembra Tavares (2002, p. 197/202), que o bem jurídico deve proteger a pessoa, mas não a norma, como o pretende os delitos de dever. Assim, é ele quem delimita a norma, o que a torna inválida quando ausente ou ileso (de dano ou perigo) o bem jurídico.

Por fim, no que tange à proporcionalidade, em Roxin (2013, p. 26/27), a legitimidade da repressão penal depende da proporcionalidade em relação ao bem jurídico protegido de lesão, à luz da proibição de excessos, e, naturalmente, da concepção do domínio penal como a ultima ratio do Direito, o que já foi mencionado no tópico anterior.

Muito embora a importância do princípio da lesividade para ordenamentos democráticos, como se observa, muitos defendem não haver expressa previsão legal no Brasil, senão normas que indiciam sua existência, como no artigo $5^{\circ}$, VI ao XII, da Constituição da República, com os direitos à intimidade e à vida privada, o que fundamenta a alteridade, como já lembrado por Zaffaroni et al (2013, p. 225).

Entretanto, Carvalho (2010) defende, acertadamente, a previsão do princípio da lesividade no ordenamento jurídico brasileiro, exatamente no artigo $5^{\circ}$, XXXV, da Constituição Federal, "estabelecendo parâmetros interpretativos para realizar juízos de invalidade das leis e dos demais atos dos Poderes Legislativo, Executivo e Judiciário." (CARVALHO, 2010, p. 210)

Mas, considerando as exigências do garantismo de Ferrajoli, este é um exemplo de um possível problema a ser enfrentado pela Teoria do Direito. Daí que, diante dos propósitos do presente trabalho, passa-se ao estudo de tal questão sob as lentes dos conceitos de Direito aqui abordados, a começar pelo garantismo. 


\section{O BEM JURÍDICO-PENAL NO POSITIVISMO DE FERRAJOLI}

A importância do bem jurídico como parâmetro de análise da eficácia do conceito de Direito adotado é evidenciada justamente em ordenamentos como o brasileiro, em que não há, dentro das reclamações do garantismo penal, suficiente previsão legal da lesividade aos bens jurídicos como condição de tipicidade, seja formal, ou mesmo material.

Desse modo, começando pelo garantismo penal, Ferrajoli (2010, p. 37) já inaugura sua obra descrevendo a "epistemologia garantista", incluindo dentre seus principais princípios a lesividade. Ou seja, Ferrajoli concorda com a importância da lesividade, a ponto de incluí-la como um dos pilares de seu sistema garantista (no axioma A4; e na tese T13, T21, T28 E T69) ${ }^{8}$.

Com isso Ferrajoli (2010, p. 433/434) elenca quatro critérios para a proteção de bens jurídicos: proibir condutas que atacam bens fundamentais (apenas dano ou perigo concreto); o valor do bem atacado deve ser maior do privado pela pena; a punição deve ser idônea a surtir efeito intimidatório; e deve ser subsidiária à política extrapenal.

Agora, para a análise da (in)existência da lesividade no ordenamento, Ferrajoli o faz sob um prisma positivista, afirmando o seguinte:

Trata-se de questões plenamente jurídicas, que não admitem como respostas juízos ou opções axiológicas, senão asserções baseadas na análise jurídico-positiva, e que, em razão disto, variam de acordo com o ordenamento analisado. Por exemplo, em muitos sistemas socialistas o requisito da lesividade é enunciado expressamente nos Códigos Penais, onde figura, contudo, não como um elemento estrutural do delito, senão como uma condição em cuja ausência se produz

8 “(...) axioma A4 nulla necessitas sine iniuria, e na tese seguinte, nulla poena, nullum crimen, nulla lex poenalis sine iniuria (T13, T21, T28, T69). Conforme Ferrajoli (2010, p. 428). 
uma eximente remetida à valoração equitativa do juiz. Em outros casos, como no italiano, a doutrina recente identifica o mesmo princípio, não reconhecido explicitamente nos arts. 43 e 49 e parágrafo do Código Penal, que requerem, respectivamente, a existência e a possibilidade de um "resultado danoso ou perigoso" como elemento estrutural do delito. Das duas soluções, que equivalem a formulações distintas da garantia da lesividade, é, talvez, preferível a segunda, desde que sob a condição de que seja formulada pela lei, não nos estritos termos do art. 49 - que a subordina à "idoneidade da ação" ou à "inexistência do objeto" -, senão mediante a aberta aceitação de que a concretização do dano ou do perigo determinados são elementos constitutivos do delito. (2010, p. 435)

Diante disto, o garantismo postula não apenas por uma expressa previsão do princípio da lesividade, mas que a mesma venha expressamente positivada como elemento estrutural do tipo penal.

$\mathrm{E}$ isto é de todo coerente com a teoria de Ferrajoli que, como já dito acima, com a separação do Direito e da Moral como paradigma, restringe a validade normativa à sua existência jurídica, compreendida esta "como produto de um ato normativo conforme as normas que regulam sua produção" (2010, p. 327), acrescida da devida positivação dos direitos naturais.

Assim, para o autor, a velha discussão entre lei natural e lei positiva perde o sentido, diante da positivação da natural. Portanto, para Ferrajoli, a análise de antinomias/incoerências entre lei e Constituição (ou lei e jurisdição ou ato administrativo etc.) é suficiente. Com isto, em Ferrajoli (2010, p. 326/329), "ser" e "dever ser" passa a ser coincidente à validade e eficácia jurídica, tudo dentro do positivado.

Neste sentido, dentro do já observado acima, o aprimoramento do positivismo normativo realizado pela teoria do garantismo penal (FERRAJOLI, 2010, p. 329/333), vem da estipulação de que as condições de validade da norma (legitimação interna) não podem se limitar ao aspecto formal (violação de procedimento, incompetência do órgão etc.), como 
ocorre com os positivistas normativistas e realistas, mas deve incluir, também, aspectos de justiça material, ou seja, o conteúdo/substância da norma em consonância com a superior, também positivada.

Aí conclui Ferrajoli (2010, p. 333/336), argumentando que é da incorporação de valores fundamentais (incorporação limitativa) às normas superiores, positivadas, que se assegura a proteção dos direitos fundamentais, sendo, o contrário, limitador do cumprimento dos referidos direitos.

Mas e os direitos fundamentais não positivados dentro dos requisitos do garantismo?

Como se observa, o garantismo penal acaba levando aos mesmos erros dos demais modelos positivistas, custando esta exclusividade do positivado em comprometimento dos direitos fundamentais "esquecidos" (ou mal lembrados) pelo legislador.

Neste sentido, o positivismo de Ferrajoli considera válidas as normas, ainda que extremamente injustas, desde que conforme às leis superiores, como a Constituição.

Mas, ainda, se enquadra nestes requisitos de positivação enunciados por Ferrajoli a lesividade do artigo 5º XXXV, da Constituição da República Brasileira?

Assim dispõe o aludido artigo 5, XXXV: “a lei não excluirá da apreciação do Poder Judiciário lesão ou ameaça a direito”.

Muito embora Carvalho (2010, p. 210) tenha defendido a validade da lesividade do referido artigo como suficiente para afastar a tipicidade material das condutas, com a insignificância, não parece ser, para Ferrajoli (2010, p. 435), tão claro isto, diante do fato de que, à luz de seu garantismo, essa previsão do artigo $5^{\circ}, \mathrm{XXXV}$, da Constituição exige, no mínimo, a equidade do juiz para a aferição da lesividade, o que, como já citado acima, ele não aconselha (FERRAJOLI, 2010, 435).

Observa-se, desta forma, que Ferrajoli defende os direitos fundamentais reconhecidos contemporaneamente, como a lesividade, mas, por limitá-los à positivação "detalhada", o faz de forma ineficaz. 
Em relação às consequências práticas, aqui no Brasil, de tal afiliação teórica, como às demais positivistas, estas serão tratadas no tópico a seguir.

\subsection{Ressonância do positivismo na jurisprudência penal brasileira}

Como alertado por Habermas (2012, p. 251), os positivistas abordam superficialmente o problema da interpretação nos "casos difíceis", acabando por culpar a imprecisão da linguagem, a considerando, muitas vezes, inevitável. Assim, especialmente os positivistas normativistas, apresentam uma solução decisionista, afirmando que, nestes casos, o juiz deve decidir conforme seu próprio arbítrio.

Isto faz o positivismo se fechar em um mundo de regras, que, se conflitarem, só o decisionismo solucionará, já que, com regras, "é tudo ou nada" (HABERMAS, 2012, p. 259).

Neste sentido, o modelo positivista de Direito, em ordenamentos que não preveem expressa e "detalhadamente" direitos fundamentais, como a exigência de lesividade para a proibição penal, formula duas possíveis soluções: nega a existência do princípio por ausência de previsão legal; ou a aceita, contudo, de forma decisionista, com a criação de critérios não jurídicos.

E esta característica - da segunda solução - de criação do Direito pelos juízes é bem afeita aos teóricos positivistas, sobretudo os normativistas, já que defendem a liberdade do juiz na abertura da lei, como Kelsen tratando da “(...) moldura dentro da qual existem várias possibilidades de aplicação, pelo que é conforme ao Direito todo ato que se mantenha dentro deste quadro ou moldura, que preencha esta moldura em qualquer sentido possível." (1994, p. 390)

Já Ferrajoli, rompendo com esta segunda solução, prefere, como já visto acima, a primeira solução, restringindo o juiz à aplicação das normas que se enquadrem no seu conceito de validade, ou seja, que estejam 
em harmonia com as normas (positivadas) superiores. Assim, como mencionado alhures, nega validade aos princípios não positivados "detalhadamente".

Em relação à primeira solução ao tratamento da lesividade nos Tribunais brasileiros, de negar a incidência por ausência (ou insuficiência) de previsão legal, apesar de os tribunais superiores já terem superado esta questão, o mesmo não ocorre nas instâncias inferiores, conforme esta ementa de julgamento de Apelação Criminal 1.0471.13.000866-0/001 (MINAS GERAIS, TJMG, 2015a) : $^{9}$

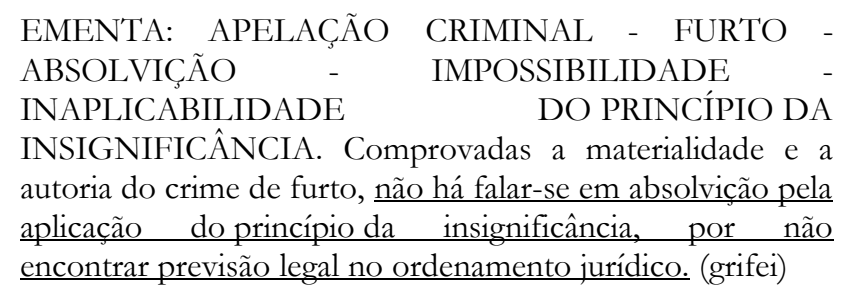

E nesta mesma linha, importante a crítica de Streck (2014b) ao concurso para Promotor de Justiça em Minas Gerais de meados de 2014, em que o espelho de correção de determinada questão indicava como resposta correta a vedação à aplicação do princípio da insignificância, diante do entendimento de ausência de previsão legal.

Nada de se surpreender, quando, conforme afirma Streck (2014a, p. 98/99), a doutrina e os cursos de Direito simplificam o ensino jurídico, com notável filiação positivista, e as exigências dos concursos públicos para magistrados, cobram tão somente autores positivistas, como Hans Kelsen ou Alf Ross (p. 112). E tudo isto ressoa na jurisprudência de nossos Tribunais.

9 No mesmo sentido, por amostragem: Apelação Criminal n ${ }^{\circ}$ 1.0313.10.0305173/001(MINAS GERAIS, TJMG, 2015b); e Apelação Criminal n $\mathrm{n}^{\circ}$ 300607502.2013.8.26.0114 (SÃO PAULO, TJSP, 2015). 
Já em relação ao decisionismo da segunda solução positivista, ainda em relação ao princípio da insignificância, o Supremo Tribunal Federal sedimentou entendimento de aceitação do princípio, porém, acrescentando critérios que não integram as noções de lesão aos bens jurídicos - expostas acima e historicamente construídas -, no HC 118853/ES (BRASIL, STF, 2014), conforme destaques da ementa a seguir:

Ementa: PENAL E PROCESSUAL PENAL. HABEAS CORPUS. FURTO QUALIFICADO (CP, ART. 155, \ $4^{\circ}$, I E IV). REINCIDÊNCIA NA PRÁTICA CRIMINOSA. PRINCÍPIO DA INSIGNIFICÂNCIA. INAPLICABILIDADE. HABEAS CORPUS EXTINTO SEM ANÁLISE DO MÉRITO. ORDEM CONCEDIDA DE OFÍCIO. 1. O princípio da insignificância incide quando presentes, cumulativamente, as seguintes condições objetivas: (a) mínima ofensividade da conduta do agente, (b) nenhuma periculosidade social da ação, (c) grau reduzido de reprovabilidade do comportamento, e (d) inexpressividade da lesão jurídica provocada. 2. A aplicação do princípio da insignificância deve, contudo, ser precedida de criteriosa análise de cada caso, a fim de se evitar que sua adoção indiscriminada constitua verdadeiro incentivo à prática de pequenos delitos patrimoniais. Em que pese haver entendimento de que somente devem ser considerados critérios objetivos para o reconhecimento dessa causa supralegal de extinção da tipicidade, a prudência recomenda que se leve em conta a obstinação do agente na prática delituosa, a fim de evitar que a impunidade o estimule a continuar trilhando a senda criminosa.

(...)

5. In casu, a conduta do paciente, como narrada na denúncia - furto qualificado pelo rompimento de obstáculo e pelo concurso de agentes -, não pode ser considerada como inexpressiva para fins penais, nem há de ser qualificada como sendo de menor afetação social. 6. O reconhecimento da atipicidade da conduta do paciente, pela adoção do princípio 
da insignificância, poderia, por via transversa, imprimir nas consciências a ideia de estar sendo avalizada a prática de delitos e de desvios de conduta, porquanto trata-se de condenado reincidente.

(...)

Decisão

Por unanimidade, a Turma julgou extinta a ordem de habeas corpus, sem julgamento do pedido formulado na inicial. Por maioria de votos, implementou a ordem, de ofício, para que o juízo substitua a pena restritiva da liberdade pela restritiva de direitos, nos termos do voto do relator, vencido o Senhor Ministro Marco Aurélio, Presidente. Não participou, justificadamente, deste julgamento, o Senhor Ministro Dias Toffoli. Primeira Turma, 29.4.2014. (grifei e recortei)

De pronto, já se pode destacar a tautologia dos quatro critérios objetivos mencionados no citado julgado (BRASIL, STF, 2014).

Como se não bastasse, trata-se de um grosseiro equívoco inserir a exigência de primariedade do acusado dentre as condições de aplicação do princípio da insignificância (BRASIL, STF, 2014), já que não é compreendida no âmbito da lesividade de bem jurídico - especialmente no contexto já apresentado no item 4 deste artigo -, por se referir a situações do autor e anteriores ao fato. Mas se amolda, pelo contrário, às condições atinentes ao "Direito Penal do Autor" 10 , claramente afeito a ordenamentos autoritários, conforme ensina Zaffaroni et al (2013, p. 131/133).

Tal postura é exatamente o decisionismo criticado por Habermas acima, já que orientada por categoria não jurídica, ou seja, nem por regras, nem por princípios.

${ }^{10}$ Importante destacar que a consideração da reincidência é ainda mais perigosa na Teoria do Crime - do que na penologia -, sobretudo na tipicidade material, como no caso, vez que acaba por definir a própria proibição - e não apenas a retribuição - a partir de elementos do Direito Penal do Autor. 
Em relação a tal atitude, complementando a censura de Habermas mencionada alhures, Neves (2014, p. XV/XVII) critica a "moldura" de Kelsen, por dar ao juiz forte discricionariedade para escolher princípios, quando da insuficiência da regra.

Ainda nas críticas, Streck (2014a, p. 165/166) afirma que os princípios vieram superar o modelo de regras do positivismo, e superar a discricionariedade do decisionismo, com o fechamento do sistema.

Desta forma, observa-se que o garantismo de Ferrajoli não é suficiente para proteger todos os direitos fundamentais que pretende assegurar, sobretudo a exigência de lesividade que, não obstante ser tão cara aos seus propósitos, caso não seja positivada - dentro de suas exigências -, o sistema lhe nega a validade e recebe a marca de baixo grau garantista ${ }^{11}$.

Daí que, apesar das críticas de Ferrajoli ao Estado liberal (2010, p. 793/797), sua teoria serve de grande valia para o Direito Penal Liberal, na medida em que não coíbe, com suficiente vigor, ordenamentos que desrespeitam os direitos fundamentais, quando não positivados.

Isto porque, como o modelo liberal possui um processo de formação da opinião pública que obedece a estruturas dos processos de mercado, com uma disputa entre as coletividades manifestada por suas preferências (HABERMAS, 1995, p. 110), o positivismo de Ferrajoli repete os mesmos erros dos demais sistemas positivistas, já que a validade jurídica é determinada pelo positivado, realizado, naturalmente, por quem detém o $\operatorname{poder}^{12}$.

${ }^{11}$ Conforme já explicado acima, Ferrajoli estabelece critérios para averiguação de graus à satisfação de seu sistema, a começar pela garantia ao seu sistema SG (FERRAJOLI, 2010, p. 91).

${ }^{12}$ Lembrando que a Lei 10.522/02 trouxe, em seu artigo 20, um comando legal que determina o arquivamento dos processos de execuções fiscais em que a União Federal cobra dívidas com valores iguais ou inferiores a $\mathrm{R} \$ 10.000,00$ (dez mil reais). Daí que a Portaria de $\mathrm{n}^{\circ} 75 / 12$, do Ministério da Fazenda, em seu artigo $1^{\circ}$, II, atualizou este valor para $\mathrm{R} \$ 20.000,00$ (vinte mil reais). Assim, sendo o Direito Penal a ultima ratio, os Tribunais 
Mas o tratamento aos direitos fundamentais penais no nãopositivismo, especialmente no conceito de Robert Alexy, é bem diferente, conforme será analisado no próximo tópico.

\section{O BEM JURÍDICO-PENAL NO NÃO-POSITIVISMO INCLUSIVO DE ALEXY}

Neste compasso, importante destacar um efetivo ranço positivista no Direito Penal, justamente por conservar a mesma estrutura de ordenamentos passados, que legitimaram estados autoritários e extremamente injustos (dentro da concepção de Alexy), portando um conceito de validade que admitia qualquer norma positivada como Direito. O Direito Penal parou no tempo em termos de Teoria do Direito, o que leva a legitimar absurdos, como negar validade a direitos fundamentais não expressamente (ou suficientemente) positivados.

Mas a conexão do Direito com a Moral, nas lentes de Robert Alexy, resolve tal problema?

Isto porque Ferrajoli (2010) justifica a separação do Direito com a Moral, dentre outros argumentos, por coibir o uso do Direito Penal para a repressão de condutas meramente morais.

Com efeito, mesmo num sistema como o de Alexy, pautado na conexão do Direito com a Moral, há limites nesta conexão - fraca, como já dito acima -, não sendo válidas normas meramente morais para repressão. A uma porque a exigência de lesividade invalidaria tais normas; a duas porque a correção material é limitada pelo princípio da nulla poena sine lege, do Direito Penal, não incidindo para punir (ALEXY, 2011, p. 71/75).

Diante disto, a conexão fraca entre Direito e Moral, nos moldes de Robert Alexy, não obsta a exigência de lesividade.

têm absolvido as acusações em crimes tributários até este montante, embora não estendam para demais crimes patrimoniais. 
Mas como o não-positivismo inclusivo de Alexy supre a falha do positivismo de Ferrajoli evidenciada quando não suficientemente previsto em lei determinado direito fundamental?

Os direitos fundamentais na Alemanha (ALEXY, 2015, p. $127 / 131$ ), possuem quatro extremos ${ }^{13}$ : regulam com o grau mais elevado (já que vêm da constituição, e invalidam leis inferiores); com a maior força executória (com o controle, sempre, pelos três poderes, especialmente o judiciário, já que: "Antes valia: direitos fundamentais somente no âmbito da lei; hoje se diz: leis somente no âmbito dos direitos fundamentais." p. 128); objetos de maior importância (regula apenas os bens fundamentais); e precisam da maior medida de abertura para sua aplicação (como o lembrado pelo autor, conceito de domićlio inviolável, se estender para espaço comercial).

Observa-se que a referida maior medida de abertura complementa as três características anteriores, a ponto de reconhecer direitos fundamentais, independente se detalhadamente (no sentido garantista) ou não previstos em leis, em perfeita sintonia com a segunda característica da maior força executória.

Daí que se admite a exigência de lesividade, ainda que não prevista em lei, já que, para quem nega a previsão, aquelas garantias individuais lembradas por Zaffaroni et al (2013, p. 225) - como os direitos à intimidade e à vida privada, previstos no artigo $5^{\circ}$, VI ao XII, da Constituição da República -, que indiciam a alteridade, legitimam a exigência de lesividade para a proibição penal, quando estendida na maior medida de abertura. Isto possibilita, também, a avocação das demais dimensões do princípio da lesividade, como a pessoalidade e a proporcionalidade já referidas acima.

${ }^{13}$ Importante destacar que, na obra, o autor explica que o sistema que abarca os quatro extremos sofre de resultados "explosivos", fato que, por estender sobremaneira o campo do conceito de Direito não é comportada a discussão neste estudo. 
Contudo, como destacado acima, a Constituição Brasileira prevê a lesividade (CARVALHO, 2010, p. 210), de sorte que, apesar de não satisfazer as exigências do garantismo penal de Ferrajoli, se adéqua muito bem ao conceito de Alexy.

Assim, as três formulações do Direito em Alexy (2011, p. 151/155), num ordenamento como o brasileiro, provocariam a seguinte consequência: como se exige a "pretensão à correção", as "normas socialmente eficazes" não podem ser "extremamente injustas", sob pena de, com o auxílio da terceira formulação, a dos "princípios" (positivados ou não) e demais "argumentos", retirar a validade de determinada norma considerada extremamente injusta.

Deste modo, a despeito das duas soluções positivistas (negação de existência ou decisionismo) para a exigência de lesividade para a proibição penal, o não-positivismo inclusivo de Alexy indica que, quando o caso concreto evidenciar que a ordem positiva inflige punição para determinada conduta com baixa (ou nenhuma) lesividade, esta norma deve ser considerada extremamente injusta pelo princípio da lesividade (embora não esteja expressa ou detalhadamente positivado) e, por decorrência, reconhecida inválida, dada à pretensão à correção.

Com isto, Alexy apresenta um conceito de Direito que consegue garantir de forma satisfatória os direitos fundamentais, sobretudo a exigência de lesividade para a proibição penal, que, em ordenamentos democráticos, ainda que com um legislador desatento - inclusive em relação às exigências do garantismo - quando da positivação, permite $\mathrm{O}$ reconhecimento e aplicação do princípio.

\section{CONSIDERAÇÕES FINAIS}

Com o exposto neste trabalho, percebe-se que o garantismo de Luigi Ferrajoli, apesar de tentar se afastar do positivismo normativista, acrescentando um aspecto substancial à norma, o que faz exigir um conteúdo coerente com o de norma superior, não deixa de desembocar em 
consequências semelhantes quando da ausência de detalhada previsão legal, ou seja, negando a existência do princípio.

Daí que o positivismo de Ferrajoli não é suficiente, especialmente em ordenamentos como o brasileiro, para garantir os direitos fundamentais que defende, a começar pela exigência de lesividade para a proibição penal, um dos pilares de sua teoria.

Já o não-positivismo inclusivo de Alexy, com a pretensão à correção, complementada pelos princípios - ainda que não expressa ou detalhadamente positivados - consegue declarar de extrema injustiça a punição de conduta com irrisório (ou inexistente) grau de lesividade, lançando mão do correspondente princípio, a ponto de retirar a validade da norma.

Com isto, observa-se que o conceito de Direito de Alexy resolve bem este problema positivista, que persiste inclusive no conceito de Ferrajoli, o que demonstra a ineficácia do garantismo penal para assegurar os direitos fundamentais que visa, sobretudo a tão defendida exigência de lesividade.

\section{REFERÊNCIAS}

ALEXY, Robert. The Argument from Injustice: a reply to legal positivism. Trad. Bonnie Litschewski Paulson, Stanley L. Paulson. Oxford, 2010.

Conceito e Validade do Direito. Trad. Gercélia Batista de Oliveira Mendes. São Paulo: WMF Martins Fontes, 2011.

- Teoria Discursiva do Direito. Organização, Tradução e Estudo Introdutório Alexandre Travessoni Gomes Trivisonno. 2. Ed. Rio de Janeiro: Forense Universitária, 2015. 
BRASIL. Supremo Tribunal Federal. Habeas Corpus 118853/ES. Relator: Luiz Fux. Diário de Justiça Eletrônico, Brasília, 29 abr. 2014. Disponível em:

<http://www.stf.jus.br/portal/jurisprudencia/listarJurisprudencia.asp?s1 $=\% 28118853 \% 2 \mathrm{ENUME} \% 2 \mathrm{E}+\mathrm{OU}+118853 \% 2 \mathrm{EACMS} \% 2 \mathrm{E} \% 29 \&$ base $=$ baseAcordaos\&url=http://tinyurl.com/qdopbqd $>$. Acesso em: 22/09/2015.

CARVALHO, Salo. A Política Criminal de Drogas no Brasil: estudo criminológico e dogmático da Lei 11.343/06. 5. Ed. Rio de Janeiro: Lumen Juris, 2010.

FERRAJOLI, Luigi. Direito e razão: teoria do garantismo penal. Trad. Ana Paula Zomer, Fauzi Hassan Choufr, Juarez Tavares, Luiz Flávio Gomes. São Paulo: Revista dos Tribunais, 2010.

Constitucionalismo principialista e constitucionalismo garantista. Trad. André Karam Trindade, In: (Org.); STRECK, Lenio Luiz (Org.); TRINDADE, André Karam (Org.). Garantismo, Hermenêutica e (Neo)Constitucionalismo: um debate com Luigi Ferrajoli. Porto Alegre: Livraria do Advogado Editora, 2012.p. 13-56.

- O constitucionalismo garantista e o estado de direito. Trad. André Karam Trindade, In: TRINDADE, André Karam (Org.). Garantismo, Hermenêtica e (Neo)Constitucionalismo: um debate com Luigi Ferrajoli. Porto Alegre: Livraria do Advogado Editora, 2012a. p. 231-254.

HABERMAS, Jürgen. Três Modelos Normativos de Democracia. Cadernos da Escola do Legislativo. Ed. Belo Horizonte: Assembleia Legislativa do Estado de Minas Gerais, v. 2, n. 3, p. 105-121, jan./jun. 1995. 
- Direito e Democracia: entre facticidade e validade. Volume 1. Trad. Flávio Beno Siebeneichler. 2. Ed. Rio de Janeiro: Tempo Brasileiro, 2012.

KELSEN, Hans. Teoria Pura do Direito. Trad. João Baptista Machado. 4. Ed. São Paulo: Martins Fontes, 1994.

MINAS GERAIS. Tribunal de Justiça. Apelação Criminal 1.0471.13.000866-0/001. Relator: Eduardo Machado. Diário de Justiça Eletrônico, Minas Gerais, 07 jul. 2015a. Disponível em: $<$ http://www5.tjmg.jus.br/jurisprudencia/pesquisaNumeroCNJEspelhoA cordao.do? numeroRegistro $=1 \&$ totalLinhas $=1 \&$ linhasPorPagina $=10 \&$ num eroUnico=1.0471.13.000866-

0\%2F001\&pesquisaNumeroCNJ=Pesquisar $>$. Acesso em: 22/09/2015.

MINAS GERAIS. Tribunal de Justiça. Apelação Criminal 1.0313.10.030517-3/001. Relator: Pedro Vergara. Diário de Justiça Eletrônico, Minas Gerais, 01 set. 2015b. Disponível em: <http://www5.tjmg.jus.br/jurisprudencia/pesquisaNumeroCNJEspelhoA cordao.do?numeroRegistro $=1 \&$ totalLinhas $=1 \&$ linhasPorPagina $=10 \&$ num eroUnico $=1.0313 .10 .030517$ -

3\%2F001\&pesquisaNumeroCNJ=Pesquisar $>$. Acesso em: 22/09/2015.

NEVES, Marcelo. Entre Hidra e Hércules: princípios e regras constitucionais. 2. Ed. São Paulo: Martins Fontes, 2014.

ROXIN, Claus. A Proteção de Bens Jurídicos Como Função do Direito Penal. Organização e Tradução de André Luís Callegari e Nereu José Giacomolli. 2. ed. Porto Alegre: Livraria do Advogado Editora, 2009.

SÃO PAULO. Tribunal de Justiça. Apelação Criminal 300607502.2013.8.26.0114. Relator: Alcides Malossi Junior. Diário de Justiça 
Eletrônico, São Paulo, 03 set. 2015. Disponível em: $<$ https://esaj.tjsp.jus.br/cjsg/resultadoCompleta.do;jsessionid=22E57941 C5DAAEBA11EBAA6A308E8C25.cjsg1 >. Acesso em: 22/09/2015.

STRECK, Lenio Luiz. Hermenêutica Jurídica e(m) Crise: uma exploração hermenêutica da construção do Direito. 11. Ed. Porto Alegre: Livraria do Advogado Editora, 2014a.

- Concurso do MP de Minas Gerais Incentiva Desobediência à Doutrina e ao STF. Conjur, 2014b. Disponível em: <http://www.conjur.com.br/2014set-04/senso-incomum-concurso-mp-minas-incentiva-desobedienciadoutrina-stf>. Acesso em: 25/09/2014.

TAVARES, Juarez. Teoria do Injusto Penal. 2. Ed. Belo Horizonte: Del Rey, 2002.

TRIVISONNO, Alexandre Travessoni Gomes. Estudo Introdutório, In: ALEXY, Robert. Teoria Discursiva do Direito. Organização, Tradução e Estudo Introdutório Alexandre Travessoni Gomes Trivisonno. 2. Ed. Rio de Janeiro: Forense Universitária, 2015. p. 1-32.

ZAFFARONI, Eugenio Raúl; BATISTA, Nilo; ALAGIA, Alejandro; SLOKAR, Alejandro. Direito Penal Brasileiro. Volume 1. 4. Ed. Rio de Janeiro: Revan, 2013. 